\title{
Nervous system involvement in systemic lupus erythematosus
}

\author{
T. GIBSON AND ALLEN R. MYERS \\ From the Section of Rheumatology, Department of Medicine, Hospital of the University of Pennsylvania, \\ Philadelphia, USA
}

\begin{abstract}
Gibson, T., and Myers, A. R. (1976). Annals of the Rheumatic Diseases, 35, 398-406. Nervous system involvement in systemic lupus erythematosus. In a retrospective analysis of 80 patients with systemic lupus erythematosus (SLE) seen over a 10-year period, $41(51 \%)$ exhibited neurological manifestations. Nervous system involvement was characterized by a significantly greater involvement of black patients $(P<0.02)$, a higher incidence of renal failure after the first appearance of neurological features $(P<0.05)$, and a significantly worse 10 -year survival rate $(P<0.05)$. Specific neurological investigations were generally unhelpful in diagnosis. The finding of hypoglycorrhachia in 4 patients was striking and may have pathogenetic significance. The lack of a specific diagnostic test for central nervous system involvement may have hindered recognition of a cerebral abscess in one patient. Treatment with massive doses of corticosteroids was not obviously more effective than treatment with smaller doses. Autopsy findings showed scattered small cerebral infarcts but vasculitis was apparent in only one case.
\end{abstract}

The recognition, treatment, and prognosis of nervous system manifestations of systemic lupus erythematosus (SLE) are notoriously difficult (Bennett and others, 1972). The clinical variability and the lack of specific diagnostic laboratory criteria may complicate distinction from the neurological sequelae of secondary metabolic disturbance, drug treatment, or incidental illness. Even when identified, it remains uncertain how neurological involvement may be most effectively treated or to what extent its occurrence influences or reflects overall prognosis.

In order to examine these questions we have summarized the clinical and laboratory characteristics of nervous system disease seen in 80 patients with SLE during a 10-year period. We have attempted to define any recognizable clinical patterns of disease, to ascertain their responses to treatment, relationship to prognosis, and where possible to review the pathological findings.

\section{Method}

The notes of all patients referred or admitted to the Hospital of the University of Pennsylvania between 1963 and 1973 with a diagnosis of SLE were reviewed. Those satisfying the preliminary diagnostic criteria, modified by substituting a high titre fluorescent antinuclear antibody as an optional alternative to positive LE cells
(Trimble and others, 1974), were reviewed in detail. All clinical, laboratory, and treatment details were plotted sequentially for each patient. Convulsive or psychotic episodes occurring for the first time in association with uncontrolled hypertension (diastolic blood pressure $>120 \mathrm{mmHg}$ ) or severe uraemia (blood urea $>16.6 \mathrm{mmol} / 1 ; 100 \mathrm{mg} / \mathrm{ml}$ ) were not considered primary manifestations of SLE and were excluded for the purpose of the study. Information about surviving patients not attending hospital was obtained from patients and their physicians. Survivors attending hospital were under regular surveillance by the authors. Recurrent episodes of the same neurological features in any one patient were recorded as a single manifestation. Onset of SLE was defined as the appearance of any one of the criteria accepted for diagnosis. A broad comparison was made between patients who exhibited nervous system involvement during the review period and those who did not. The results of investigations were reviewed.

An attempt was made to compare the response of neurological manifestations to corticosteroid therapy. Three arbitrary treatment groups were defined comprising low daily dose of prednisone ( $<30 \mathrm{mg}$ ), an intermediate dose range $(30-100 \mathrm{mg})$, and massive doses $(>100 \mathrm{mg}$ ). Those patients recovering or substantially improving within 3 weeks of starting treatment were categorized as showing an improved response. This group could be easily distinguished from patients who relapsed or died during the same period. Autopsy findings of patients 
whose deaths were presumed to be due to nervous system involvement were reviewed.

\section{Results}

Eighty patients satisfied the diagnostic criteria for SLE. Of these, 41 (51\%) developed neurological disease at some time during a median follow-up period of 7 years (range 1-23 years).

\section{CLINICAL FEATURES}

There were 99 manifestations of nervous system involvement excluding recurrences of the same feature in any one subject (Table I). The mean age of onset of nervous system involvement was $32 \cdot 3$ years with a mean interval of $5 \cdot 3$ years after the onset of SLE. Neurological features occurred relatively early in the course of the disease in the majority of cases (median 2 years after onset of SLE) but the range was considerable (0-22 years). 3 patients exhibited neurological features during the presenting illness but none of these appeared in the absence of other features of SLE.

Psychotic disorders were the most common feature $(27 \%)$, followed by convulsions $(20 \%)$, headaches $(17 \%)$, and hemiplegia $(10 \%)$. Two different simultaneous manifestations occurred in 16 patients, three in 6 patients, and four in 2 patients. The most common combination of features was that of convulsions and psychosis, observed in 6 cases $(15 \%)$. Headache was the single most common feature associated with other manifestations, occurring in 11 cases $(27 \%)$. Simultaneous manifestations were probably due to closely related anatomic lesions in most instances, e.g. convulsions and psychosis, but in 3 patients concurrent features

Table I Neuropsychiatric manifestations in 80 patients with SLE

\begin{tabular}{llr}
\hline Manifestation & \multicolumn{1}{l}{ Number (\%) } \\
\cline { 1 - 1 } $\begin{array}{ll}\text { Psychoses: } \\
\text { Depressive }\end{array}$ & $27(27 \%)$ & 5 \\
$\quad$ Schizophrenic & & 3 \\
Confusional state & $20(20 \%)$ & 19 \\
Henvulsions & $17(17 \%)$ \\
Hemiplegia & $10(10 \%)$ \\
Papilloedema & $5(5 \%)$ \\
Cranial nerve palsy & $4(4 \%)$ \\
Paraplegia & $3(3 \%)$ \\
Pseudobulbar palsy & $3(3 \%)$ \\
Cerebellar ataxia & $2(2 \%)$ \\
Peripheral neuropathy & $2(2 \%)$ \\
Chorea & $2(2 \%)$ \\
Visual field defect & $2(2 \%)$ \\
Aseptic meningitis & $1(1 \%)$ \\
Temporal lobe epilepsy & $1(1 \%)$ \\
\hline Total & 99 \\
\hline
\end{tabular}

Table II Details of 3 patients with simultaneous neurological manifestations affecting widely separated sites

\begin{tabular}{|c|c|}
\hline Case no. & Simultaneous manifestations \\
\hline $\begin{array}{l}1 \\
2 \\
3\end{array}$ & $\begin{array}{l}\text { Psychosis; peripheral neuropathy } \\
\text { Headache; peripheral neuropathy } \\
\text { Convulsions; paraplegia; pseudobulbar palsy }\end{array}$ \\
\hline
\end{tabular}

affected widely separate anatomic sites (Table II). One or more recurrences of the same manifestation occurred in 14 patients at intervals varying from 2 weeks to 6 years. From two to five different consecutive features occurred in 17 patients with similar varying intervals.

Comparison between those patients with neurological involvement and those with none showed some differences (Table III). The age of onset of SLE, sex distribution, and the mean follow-up periods were not significantly different among the groups. A significantly larger proportion of black patients had nervous system disease, a difference not explained by variations in the mean $( \pm S D)$ of follow-up times between black $(7 \cdot 4 \pm 5 \cdot 3$ years) and white patients $(9 \cdot 0 \pm 6 \cdot 3$ years), which were not significantly different $(t=1 \cdot 2)$. The incidence of serositis, arthritis, rashes, haematological and renal involvement (as determined by proteinuria, urine casts, or biopsy) was similar in both groups. However, patients with established nervous system disease developed uraemia $(41 \%)$ more frequently at a later date than those with no nervous system involvement $(20 \%)$, and this difference was significant $(P<0.05)$ (Table IV).

\section{LABOR ATORY INVESTIGATIONS}

Serum complement (C3 or $\mathrm{CH}_{50}$ ) was lowered in 24 of the 30 episodes in which this was measured.

Table III Comparison between patients with and without a history of nervous system involvement

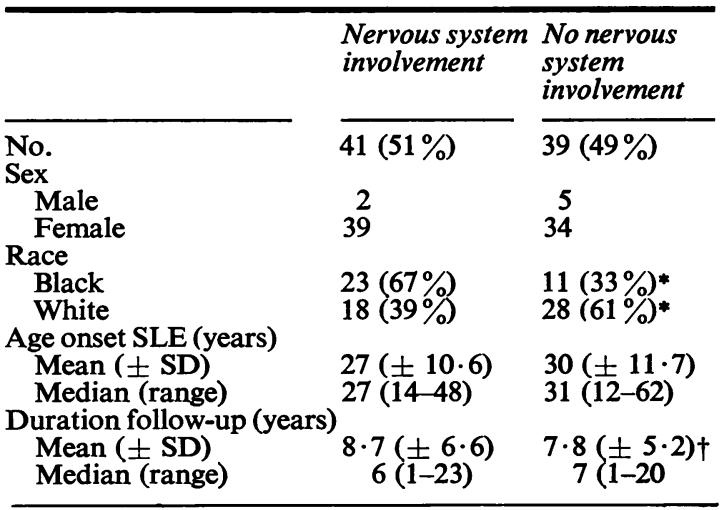

$\chi^{2}=6.3 ; P<0.02 ; \dagger t=0.61$; not significant. 
Table IV Comparison of clinical features of patients with and without a history of nervous system involvement

\begin{tabular}{|c|c|c|}
\hline \multirow[t]{2}{*}{ Clinical feature } & Nervous system involvement & No nervous system involvement \\
\hline & No. of patients $(\%)$ & No. of patients $(\%)$ \\
\hline $\begin{array}{l}\text { Arthritis } \\
\text { Serositis } \\
\text { Rash } \\
\text { Alopecia } \\
\text { Haematological abnormality } \\
\text { Raynaud's phenomenon } \\
\text { Glomerulonephritis } \\
\text { Uraemia (blood urea }>10 \mathrm{mmol} / \mathrm{l}) \\
(>60 \mathrm{mg} / 100 \mathrm{ml})\end{array}$ & $\begin{array}{l}33(80 \%) \\
20(49 \%) \\
20(49 \%) \\
18(44 \%) \\
25(60 \%) \\
6(15 \%) \\
26(63 \%)\end{array}$ & $\begin{array}{l}36(92 \%) \\
24(61 \%) \\
27(69 \%) \\
11(38 \%) \\
27(69 \%) \\
6(15 \%) \\
20(50 \%)\end{array}$ \\
\hline $\begin{array}{l}\text { Before onset of neurological disease } \\
\text { Overall } \\
\text { Survival from onset SLE }\end{array}$ & $\begin{array}{l}7(17 \%) \\
17(41 \%)\end{array}$ & $\overline{8}(20 \%) *$ \\
\hline $\begin{array}{l}5 \text { years } \\
10 \text { years }\end{array}$ & $\begin{array}{l}27 / 34(79 \%) \\
13 / 26(50 \%)\end{array}$ & $\begin{array}{l}28 / 31(90 \%) \\
15 / 18(83 \%) \dagger\end{array}$ \\
\hline
\end{tabular}

$* \chi^{2}=4.1 ; P<0.05 .+\chi^{2}=5.1 ; P<0.05$.

Anti-DNA antibodies were determined in only six episodes and were abnormal in all six. No attempt was made to measure DNA antibodies serially. Lumbar punctures were performed once or more in 51 episodes of nervous system disease. Abnormalities were detected in $18(33 \%)$ of these and comprised mildly raised protein in $15(27 \%)$, slight pleocytosis in $3(6 \%)$, and a low CSF sugar in 4 $(8 \%)$. The raised protein values ranged from $5 \cdot 3$ to $3.89 \mathrm{~g} / 1(53-389 \mathrm{mg} / 100 \mathrm{ml})$ with a mean of $1 \cdot 16 \mathrm{~g} / 1$ $(116 \mathrm{mg} / 100 \mathrm{ml})$; the raised white cell counts were $0.002,0.022$, and $0.385 \times 10^{9} / 1\left(2,22\right.$, and $\left.385 / \mathrm{mm}^{3}\right)$. The last count contained $70 \%$ polymorphs but the other two consisted entirely of lymphocytes. Details of patients exhibiting low CSF sugar are illustrated in Table V. All 4 patients had at least one value which was $<2.2 \mathrm{mmol} / 1(40 \mathrm{mg} / 100 \mathrm{ml})$. Cultures and stains showed no infectious organisms in these cases.

Electroencephalograms were performed on 27 occasions. An abnormality was detected in 31 (84\%) of these and comprised nonspecific generalized slowing in $21(57 \%)$, and focal or lateral slowing features or discharges in $16(43 \%)$. Brain scan abnormalities occurred in only $4(19 \%)$ out of 21 cases. 3 of the positive cases had hemiparesis and the fourth a psychosis associated with papilloedema. Carotid arteriography was performed in 2 cases of hemiplegia and showed what were considered to be emboli occluding major branches of middle cerebral arteries.

\section{TREATMENT}

In general, once nervous system involvement by SLE was assumed, the major therapeutic consideration was whether to treat with the massive doseo of corticosteroids advocated by Dubois (1974) There was no consistent policy in this regard and the use of very high, intermediate, or small doses of steroids reflected the divergent opinions prevalent Invariably, anticonvulsants were prescribed in conjunction with corticosteroids for convulsive disorders. Similarly, psychotropic drugs were used with steroids in the management of nearly all psychotic disorders and in all the cases whose responses to treatment are analysed below.

Twenty-three patients $(56 \%)$ were receiving corticosteroids before the initial onset of nervous system disease, 13 in doses equivalent to $<30 \mathrm{mg}$ prednisone daily, and 10 in doses ranging between $30 \mathrm{mg}$ and $100 \mathrm{mg}$ daily. In 3 patients neurological symptoms developed for the first time during rapid reduction of steroid dosage, and in 3 others psychotic behaviour developed during treatment with doses of prednisone $>100 \mathrm{mg}$ daily.

There was sufficient documentation to allow some

Table V Details of 4 patients with low CSF sugar

\begin{tabular}{|c|c|c|c|c|c|}
\hline \multirow{2}{*}{$\begin{array}{l}\text { Case } \\
\text { no. }\end{array}$} & \multirow{2}{*}{$\begin{array}{l}\text { Clinical } \\
\text { manifestations }\end{array}$} & \multicolumn{3}{|l|}{$C S F$} & \multirow{2}{*}{$\begin{array}{l}\text { Simultaneous } \\
\text { blood sugar } \\
\text { mmol/l }(\mathrm{mg} / 100 \mathrm{ml})\end{array}$} \\
\hline & & $\begin{array}{l}\text { Sugar } \\
\mathrm{mmol} / \mathrm{l}(\mathrm{mg} / 100 \mathrm{ml})\end{array}$ & $\begin{array}{l}\text { Protein } \\
g / l(m g / 100 m l)\end{array}$ & $\begin{array}{l}W B C \\
\times 10^{9} / l\left(\mathrm{~mm}^{3}\right)\end{array}$ & \\
\hline $\begin{array}{l}3 \\
4 \\
5 \\
6\end{array}$ & $\begin{array}{l}\text { Paraplegia } \\
\text { Convulsions } \\
\text { (a) Cerebellar ataxia } \\
\text { (b) Psychosis } \\
\text { Psychosis }\end{array}$ & $\begin{array}{l}0 \cdot 55(10) \\
1 \cdot 11(20) \\
1 \cdot 94(35) \\
2 \cdot 49(45) \\
1 \cdot 94(35)\end{array}$ & $\begin{array}{l}0 \cdot 53(53) \\
1 \cdot 54(154) \\
0 \cdot 3(30) \\
0 \cdot 34(34) \\
0 \cdot 24(24)\end{array}$ & $\begin{array}{l}0 \cdot 003(3) \\
0 \cdot 022(22) \\
0 \\
0 \\
0\end{array}$ & $\begin{array}{c}3 \cdot 5(64) \\
4 \cdot 9(90) \\
- \\
18 \cdot 31(330) \\
6 \cdot 66(120)\end{array}$ \\
\hline
\end{tabular}


Table VI Details of 52 separate neurological episodes and response to corticosteroid therapy in various doses

\begin{tabular}{|c|c|c|c|c|c|c|c|}
\hline $\begin{array}{l}\text { Treatment group } \\
\text { (daily prednisone) }\end{array}$ & Outcome & Convulsions & Psychosis & Hemiplegia & Headache & Papilloedema & Total \\
\hline \multirow{2}{*}{$\begin{array}{l}\text { Massive dose } \\
(>100 \mathrm{mg})\end{array}$} & Improved & 2 & 5 & - & - & 2 & $9(60 \%$ \\
\hline & Relapsed & 2 & 2 & 2 & - & - & $6(40 \%)$ \\
\hline \multirow{2}{*}{$\begin{array}{l}\text { Intermediary dose } \\
(30-100 \mathrm{mg})\end{array}$} & Improved & 5 & 5 & 3 & 2 & - & $15(83 \%)$ \\
\hline & Relapsed & - & - & 2 & - & 1 & $3(17 \%)$ \\
\hline \multirow{2}{*}{$\begin{array}{l}\text { Low dose } \\
(<30 \mathrm{mg})\end{array}$} & Improved & 3 & 3 & 3 & 2 & 1 & $12(63 \%)$ \\
\hline & Relapsed & - & 4 & 3 & - & - & $7(37 \%)$ \\
\hline Total & & 12 & 19 & 13 & 4 & 4 & 52 \\
\hline
\end{tabular}

conclusion about the response to corticosteroid treatment in $\mathbf{5 2}$ separate episodes of nervous system involvement. The major clinical features treated were evenly distributed throughout the three arbitrary treatment groups of very high, intermediate, or small doses of corticosteroids (Table VI). The groups were not comparable in other respects and in particular hypertension, mild uraemia, or both were present in $8(55 \%)$ of the high dose group, in $4(20 \%)$ of the intermediate dose group, and in one of the low dose group.

The numbers were too small to allow statistical analysis of the effect of treatment on specific neurological features and the details are summarized in Table VI. Overall, more patients treated with intermediate doses of steroids improved within 3 weeks $(83 \%)$ than patients receiving low $(63 \%)$ or massive doses $(60 \%)$. However, this difference was not significant $\left(\chi^{2}=2 \cdot 25\right)$. It is worth noting that 10 patients with convulsions or psychosis treated with intermediate doses of steroid recovered, whereas only 13 of 21 cases treated with massive or low doses did so.

\section{PROGNOSIS}

During the follow-up period 22 patients died and the major causes ascribed at the time of death are given in Table VII. 19 were patients who exhibited neurological symptoms but only $6(27 \%)$ were thought to have succumbed to nervous system disease.
A history of neurological involvement was associated with worse 5- and 10-year survival rates from the time of onset of SLE (Table IV). The difference was significant at 10 years $\left(\chi^{2}=5 \cdot 1\right.$; $P<0.05)$, but not at 5 years $\left(X^{2}=1 \cdot 48\right)$. The mean survival time of the neurological patients who died was 2 years from the first nervous system manifestation (range 1 month-9 years). Their mean age $( \pm$ SD) at the time when these features first appeared was $29 \pm 11.5$ years, similar to that of the neurological patients still alive at the end of the review period (30 \pm 9.5 years). Their racial distribution comprised 12 black $(63 \%)$ and 7 white patients $(37 \%)$, a ratio almost identical to that of the neurological subjects as a whole (Table III). The major manifestations occurring nearest death were psychoses (32\%), convulsions $(27 \%)$, headache $(15 \%)$, and hemiplegia $(10 \%)$, a percentage distribution similar to that seen in the series overall (Table I). One-year survival from the onset of psychosis occurring in isolation was $14 / 16(87 \%)$ and of convulsions $9 / 13(69 \%)$, an insignificant difference $\left(X^{2}=1 \cdot 7\right)$. Numbers of isolated manifestations and duration of follow-up were insufficient to allow meaningful comparison of survival for other manifestations and survival rates beyond one year.

\section{PATHOLOGY}

The major autopsy findings of the 6 patients whose deaths were attributed to nervous system involvement are outlined in Table VIII. Scattered haemorrhagic

Table VII Causes of death in 22 patients with SLE

\begin{tabular}{lllll}
\hline Cause & No. of patients & & Total (\%) \\
\cline { 2 - 3 } & Nervous system involvement & No nervous system involvement & \\
\hline Renal failure & 7 & 2 & $9(40 \%)$ \\
Neurological & 6 & - & $6(27 \%)$ \\
Infection & 4 & - & $4(20 \%)$ \\
Unknown & 2 & 1 & $2 \%$ \\
Haemorrhage & - & & $1(4 \%)$ \\
\hline
\end{tabular}


Table VIII Major pathological findings in the CNS of 6 patients whose deaths were ascribed to nervous system involvement

\begin{tabular}{|c|c|c|c|c|}
\hline \multirow{2}{*}{$\begin{array}{l}\text { Case } \\
\text { no. }\end{array}$} & \multirow{2}{*}{$\begin{array}{l}\text { Age at } \\
\text { death } \\
\text { (years) }\end{array}$} & \multicolumn{2}{|c|}{ Nervous system manifestations } & \multirow[t]{2}{*}{ Major autopsy findings } \\
\hline & & At death & Previous & \\
\hline 7 & 22 & Hemiplegia & - & $\begin{array}{l}\mathbf{R} \text { middle cerebral artery occlusion; } \\
\text { widespread atheroma; } \\
\text { old and fresh cerebral infarcts }\end{array}$ \\
\hline 8 & 57 & $\begin{array}{l}\text { Confusional } \\
\text { state }\end{array}$ & $\begin{array}{l}\text { Psychosis; } \\
\text { convulsions }\end{array}$ & $\begin{array}{l}\text { Isolated haemorrhagic infarcts; } \\
\text { plugging of small vessels with hyaline materia }\end{array}$ \\
\hline 9 & 19 & $\begin{array}{l}\text { Convulsions; } \\
\text { confusional } \\
\text { state }\end{array}$ & $\begin{array}{l}\text { Aseptic meningitis; } \\
\text { papilloedema; } \\
\text { psychosis; } \\
\text { convulsions }\end{array}$ & $\begin{array}{l}\text { Small haemorrhagic infarcts; } \\
\text { plugging small veins with hyaline material }\end{array}$ \\
\hline 10 & 38 & $\begin{array}{l}\text { Status } \\
\text { epilepticus }\end{array}$ & $\begin{array}{l}\text { Psychosis; } \\
\text { cranial nerve palsy; } \\
\text { hemiplegia; } \\
\text { convulsions }\end{array}$ & $\begin{array}{l}\text { Thrombosis superior sagittal sinus; } \\
\text { scattered micro-infarcts }\end{array}$ \\
\hline 11 & 59 & Hemiplegia & Peripheral neuropathy & $\begin{array}{l}\text { Diffuse haemorrhagic infarction; } \\
\text { vascular and perivascular cell infiltrates }\end{array}$ \\
\hline 12 & 23 & $\begin{array}{l}\text { Convulsions; } \\
\text { psychosis }\end{array}$ & $\begin{array}{l}\text { Convulsions; } \\
\text { psychosis }\end{array}$ & $\begin{array}{l}\text { Large abscess occipital lobe; } \\
\text { scattered small infarcts; } \\
\text { hypertrophy walls medium sized arteries }\end{array}$ \\
\hline
\end{tabular}

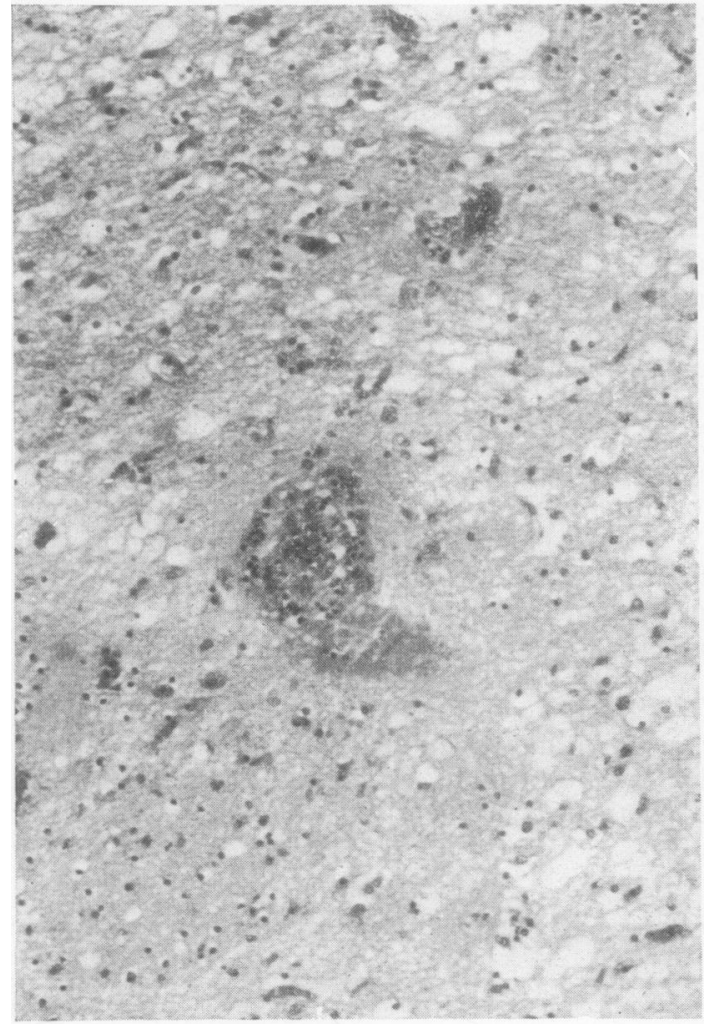

(a)

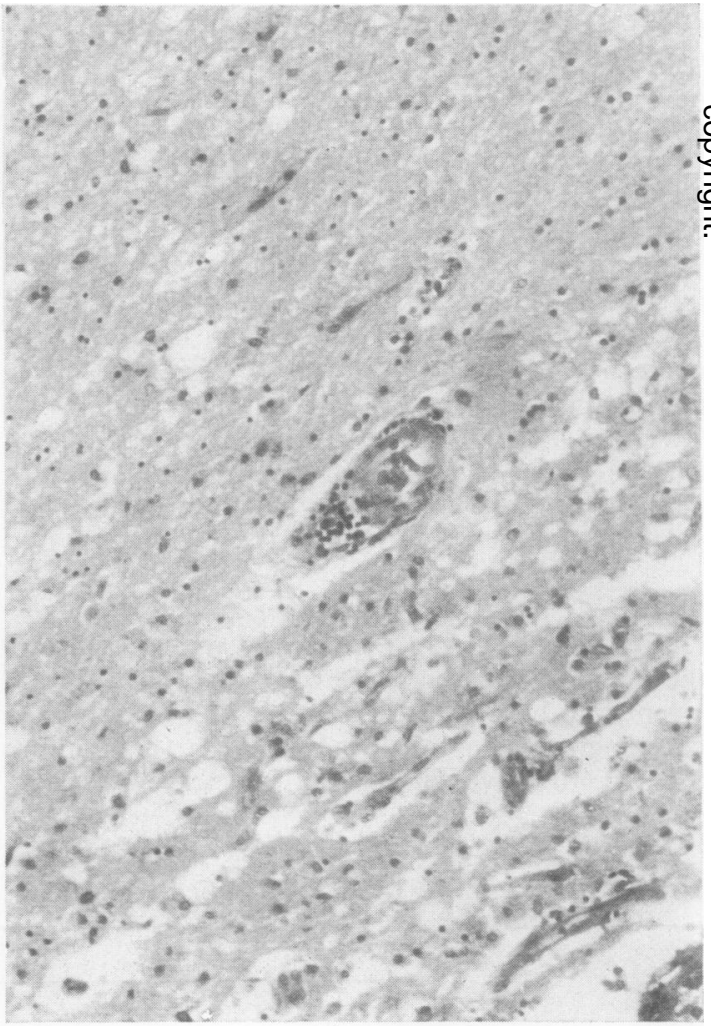

(b)

FIGURE (a) Section of cerebral cortex in one patient (Case 11) showing infiltration of vessel walls by polymorph and chronic inflammatory cells. Haematoxylin and eosin. $\times 82 ;(b)$ showing perivascular infiltration by inflammatory cells. Haematoxylin and eosin. $\times 82$ 
infarcts of varying size were seen in the cerebral hemispheres of all 6 subjects. These were visible to the naked eye in 5 cases but were apparent as small petechiae in one case (Case 9) and could be detected only under the microscope in another (Case 11). Microscopy showed more widespread areas of necrosis than were obvious in all six of the gross specimens. These changes were accompanied by plugging of small vessels with hyaline material in 2 patients (Cases 8 and 9) but the vessel walls were normal in these instances. Hypertrophy of all layers of the medium-sized arteries was seen in one patient (Case 12). Vascular and perivascular infiltration with chronic inflammatory cells and polymorphs were features of another (Case 11) and were the only evidence of vasculitis (Figure $a$ ) and perivasculitis (Figure $b$ ).

In one patient (Case 1) there was extensive occlusion of the right middle cerebral artery by thrombus. Smaller thrombi were also apparent in the left middle cerebral artery and the major branches of both vessels. Whether these changes were intimately related to SLE or to the widespread atheroma present in the same patient were not clear. Extensive thrombosis of the superior sagittal sinus was another thrombotic feature seen in another case (Case 10).

The presence of a large abscess cavity in Case 12 was unsuspected in life. No organism could be cultured but the aetiology was presumed to be infective. Scattered infarcts in this patient suggested an additional pathological process but it is likely that the abscess contributed largely if not solely to death. Silver staining and immunofluorescence studies were performed on the choroid plexus of the case with extensive thrombosis but these failed to show any structural abnormality or immunoglobulin deposition in the plexus vessels.

\section{Discussion}

Neurological involvement in SLE has been recognized since Osler's description of the disease (1895). Innumerable manifestations have been described and many examples were seen in this series. Psychotic disorders, comprising mainly acute confusional states, were the most common indication of neurological involvement, followed by grand mal convulsions, headaches, and hemiplegia. The relative frequency of the more common features was similar to that of earlier reports (Johnson and Richardson, 1968).

Less frequent manifestations are worth comment since their association with SLE is often not appreciated, particularly in the absence of other signs. Although not apparent in this study, neurological signs may precede other features by years (Siekert and Clark, 1955), and the difficulties of establishing a correct diagnosis have been emphasized when paraplegia (Penn and Rowan, 1968), chorea (Lusins and Szilagyi, 1975), papilloedema (Silberberg and Laties, 1973; Carlow and Glaser, 1974), or aseptic meningitis (Canoso and Cohen, 1975) occur in the absence of the classical features of SLE.

Why neurological involvement should afflict only a proportion of patients is as uncertain as many aspects of this illness. Recurrence of the same feature in 14 and the involvement of different sites consecutively or simultaneously in many of our patients suggests a particular predilection for neurological involvement in some cases. The relatively higher incidence of neurological disease among black patients in this study was a striking and unexpected finding. Other series have not commented upon any racial disparity in this respect. Theoretically, our finding might have been due to a selection bias. The spectrum of SLE in the community at large encompasses a group with more benign illness than that commonly encountered in a hospital environment (Fessel 1974) and any process which favoured selection of the severely ill black patients would provide a speculative explanation for our observations. However, while it is true that this hospital series probably distorts the overall picture of SLE by virtue of the severe cases referred from other institutions, there was no obvious selection with regard to race.

The group of patients with neurological disease was further characterized by a tendency to develop more severe renal disease. Care was taken to exclude those patients in whom uraemia was the likely cause of initial nervous system manifestations and therefore a cause and effect relationship does not apply. However, to what extent the subsequent development of severe renal failure precipitated or prolonged recurrent neurological episodes in these patients is not clear.

As yet, there is no specific routine laboratory procedure which can confirm suspected nervous system involvement. Precise assessment is difficult in the face of concomitant uraemia, hypertension, or infection, and the role of high-dose corticosteroids in the aetiology of psychoses poses a special and unresolved problem (Decker and others, 1975). The diagnosis often rests on the basis of clinical or laboratory evidence suggesting an associated increase of disease activity, but these may prove to be woefully inadequate criteria.

Abnormalities of the CSF may help distinguish organic from functional disease (Bennett and others, 1972) and our finding of pleocytosis and mildly raised CSF protein in one-quarter of those examined is similar to previous reports (Johnson and Richardson, 1968). These are nonspecific observations and their absence in the majority emphasizes that 
normal CSF on routine testing is the rule rather than the exception.

The demonstration of low CSF sugar in 4 patients was of particular interest. A similar observation has been made recently in 3 cases of transverse myelopathy due to SLE (Andrianakos and others, 1975). CSF sugar is normally $60-70 \%$ of the blood level, assuming no rapid fluctuations (Fishman, 1964). In our 4 cases CSF sugar was less than $30 \%$ of simultaneous blood sugar levels and less than $2 \cdot 2 \mathrm{mmol} / \mathrm{l}$ $(40 \mathrm{mg} / 100 \mathrm{ml})$ on at least one occasion. Levels in this range are unequivocally low (Prockop, 1972). Hypoglycorrhachia is occasionally seen in meningeal carcinomatosis (Kim and Resnick, 1965) and sarcoidosis (Wiederholt and Siekert, 1965) and the mechanism is presumed to reflect disturbance of the meningeal transport system between blood and CSF. A similar mechanism could conceivably account for the phenomenon in SLE, particularly since meningeal involvement is now a recognized feature (Canoso and Cohen, 1975). Disease of the choroid plexus might also disturb the blood CSF barrier (Prockop, 1972) and since desposition of immunoglobulin in the choroid plexus has been invoked as one explanation for neurological disease in SLE (Atkins and others, 1972) disturbance of choroid plexus function offers an alternative but speculative mechanism for our observation.

Claims have been made that lowered levels of CSF complement (C4) are highly indicative of active central nervous system disease (Petz and others, 1971). However, in another series, CSF C4 levels were not found to be lower than in controls although they did tend to fall in a small number whose CSF was examined serially (Hadler and others, 1971). In our own laboratory, assay of CSF $\mathrm{C} 4$ was found to be unhelpful because $\mathrm{C} 4$ deteriorated rapidly even when frozen; the test was not reproducible on a day-to-day basis and in addition its determination failed to distinguish SLE patients with nervous system involvement from other SLE patients (E. P. Gall, personal communication, 1975). Whether the measurement in the CSF of DNA antibodies (Lindström and Anders 1975) or DNAanti-DNA complexes (Keeffe and others, 1974) will provide the necessary means of confirming lupus involvement of the nervous system, remains to be seen.

The value of EEGs is doubtful since although positive in $84 \%$ of those patients in whom it was performed, the findings were entirely nonspecific. Similar observations and conclusions have been previously reported (Johnson and Richardson, 1968). Brain scans were equally unhelpful in our experience, being positive in only $19 \%$ of cases and usually where gross pathology could be anticipated. This is in direct contrast to the view of Bennahum,
Messner, and Shoop (1974), who suggested that it was a sensitive tool in the detection of cerebral lupus. The misinterpretation of abnormal scans due to focal infection in SLE has been recently emphasized (Stewart and Basten, 1975) and is an obvious hazard of this technique.

Large cerebral vessel occlusion may be a feature of SLE (Silverstein, 1963) and carotid arteriography may show such cases. Cerebral arteriographic changes suggesting inflammation of large vessels have been described in SLE(Trevor and others, 1972). However, arteriograms are difficult to interpret with certainty and in the 2 cases where this investigation was performed in the current study, occlusion was attributed to emboli. One of these cases died and at autopsy there was thrombosis and atheroma of the middle cerebral arteries but no source of embolus (Case 1, Table VIII).

The management of SLE patients with central nervous system disease is difficult since such involvement is often acute, unexpected, and potentially lethal. In this situation the case for an emphatic therapeutic approach is tempting and often takes the form of massive doses of corticosteroid as advocated by Dubois (1974). Analysis of the response to corticosteroid treatment in our study was difficult because the information was obtained retrospectively; patients in the three steroid treat-co ment groups were unmatched and almost certainly the concurrence of advancing renal disease and prior steroid treatment influenced the choice of a very high dose regimen in some cases. Nevertheless, massive doses of prednisone in excess of $100 \mathrm{mg}$ daily were not associated with a uniformly beneficial effect nor was there a clear advantage over the use of smaller doses. Other retrospective studies have reached similar conclusions (Johnson and Richardson, 1968), and Sergent and others (1975) have not only confirmed this opinion but have suggested that massive doses of corticosteroids increase morbidity. The correct therapeutic approach to the medical emergency caused by central nervous system SLE has yet to be defined by prospective evaluation.

In the present series prognosis was adversely affected by the occurrence of neurological involvement. This finding is in agreement with the prospective analysis of Estes and Christian (1971). However, it has been suggested that neurological involvement has diminished as a cause of death and is now a less frequent cause than uraemia (Dubois and others, 1974). Our findings agree with this. Nervous system involvement was only $65 \%$ as common a cause of death as uraemia and was equal with infection in this respect. The cause of death in the patients with neurological disease and the observation that a history of neurological disease can be statistically linked with the subsequent 
development of severe renal disease suggests that the worse prognosis is not necessarily related to nervous system involvement per se but implies a group of patients with a generally more severe form of the disease.

Age at the time of neurological involvement did not seem to affect survival, nor did race. This is in contrast to a recent study in which mortality of patients with neurological involvement was greatest in whites over 30 years and least in blacks under 30 years of age (Sergent and others, 1975). The predominance of black patients with neurological involvement in our survey might be reflected in survival statistics from other sources if the findings were generally relevant. There is some disagreement about the effect of race on survival in SLE. Estes and Christian (1971) could find none, but Siegel and Seelenfreund (1965) showed a worse overall prognosis for black patients, and this could be compatible with our finding.

No specific neurological manifestation was more common among those patients who died, and survival after one year was no worse for convulsions than psychosis. Long-term survival for specific manifestations could not be assessed from our data but there is some evidence to suggest that organic brain syndromes are related to a worse 5-year survival than other neuropsychiatric features (Estes and Christian, 1971).

Autopsy studies of patients who have died with nervous system involvement add little to the understanding of the pathogenesis. Our finding of isolated cerebral infarcts which were more widespread when examined microscopically together with the plugging of small vessels with hyaline material suggests focal lesions commonly presumed to be caused by vasculitis. These findings and the demonstration of true vasculitis in only one instance echo the ob- servations made by Johnson and Richardson (1968). In their comprehensive study, a specific neuropathological lesion could not be identified. It was not possible to confirm the deposition of immunoglobulin in the choroid plexus (Atkins and others, 1972 ) in the one case examined in this manner.

The pathological changes may be more instructive when unsuspected features are disclosed. Major vessel thrombosis in one patient age 22 years (Case 1, Table VIII) was thought due to primary SLE involvement, but despite the patient's age the associated atheroma may well have been causative or at least contributory. Accelerated atheroma of the coronary arteries in young patients with SLE has been described (Bulkley and Roberts, 1975) illustrating premature atherosclerosis in an analogous situation. It is very likely that such observations are either the direct consequence of high dose corticosteroid therapy or secondary to the induction of risk factors, e.g. hyperlipidaemia or diabetes.

The unexpected finding of a temporal lobe abscess in one patient (Case 12, Table VIII) has disturbing implications. The patient had recurrent episodes of nervous system manifestations identical to those of her terminal illness and there was evidence of diffuse brain disease at autopsy. Examination of CSF was normal but an EEG showed a focal lesion in the temporal lobe. Although it is possible that active central nervous system involvement was present during the illness immediately preceding death, there was no means of confirming or refuting this with confidence. This case exemplifies the need for a simple, speedy, and reproducible method of establishing nervous system involvement in SLE.

The authors gratefully acknowledge the support provided by the Arthritis Foundation and the Barsumian Fund.

\section{References}

Andrianakos, A. A., Duffy, J., Suzuki, M., ANd Sharp, J. T. (1975) Ann. intern Med., 83, 616 (Transverse myelopathy in SLE. Report of three cases and review of the literature)

Atrins, C. J., Kondon, J. J., QUismorio, F. P., AND FrIou, G. J. (1972) Ibid, 76, 65 (The choroid plexus in systemic lupus erythematosus)

Bennahum, D. A., Messner, R. P., AND Shoop, J. D. (1974) Ibid., 81, 763 (Brain scan findings in central nervous system involvement by lupus erythematosus)

Bennett, R., Hughes, G. R. V., Bywaters, E. G. L., AND Holt, P. J. L. (1972) Brit. med. J., 4, 342 (Neuropsychiatric problems in systemic lupus erythematosus)

Bulkiey, B. H., AND RoBerTs, W. C. (1975) Amer. J. Med., 58, 243 (The heart in systemic lupus erythematosus and the changes induced in it by corticosteroid therapy)

Canoso, J. J., AND Cohen, A. S. (1975) Arthr. and Rheum., 18, 369 (Aseptic meningitis in systemic lupus erythematosus. Report of three cases)

Carlow, T. J., AND Glaser, J. S. (1974) J. Amer. med. Ass., 228, 197 (Pseudotumor cerebri syndrome in systemic lupus erythematosus)

Decker, J. L., Steinberg, A. D., Gershwin, M. E., Seaman, W. E., Klippel, J. H., Plotz, P. H., and Pagft, S.A. (1975) Ann. intern. Med., 82, 391 (Systemic lupus erythemetosus, contrasts and comparisons)

Duвors, E. L. (1974) 'Lupus Erythematosus', 2nd ed., p. 596. University of Southern California Press, Los Angeles

-, WierzChOWIECKI, M., Cox, M. B., AND WeINER, J. M. (1974) J. Amer. med. Ass., 227, 1399 (Duration and death in systemic lupus erythematosus) 
Estes, D., AND Christian, C. L. (1971) Medicine, 50, 85 (The natural history of systemic lupus erythematosus by prospective analysis)

Fessel, W. J. (1974) Arch. intern. Med., 134, 1027 (Systemic lupus in the community)

Fishman, R. A. (1964) Amer. J. Physiol., 206, 836 (Carrier transport of glucose between blood and cerebrospinal fluid)

Hadler, N. M., Gerwin, R. D., Frank, M. M., Whitaker, J. N., BaKer, M., AND DeCKer, J. L. (1971) Arthr. and Rheum., 16, 507 (The fourth component of complement in the cerebrospinal fluid in systemic lupus erythematosus)

Johnson, R. T., AND RICHARDson, E. P. (1968) Medicine, 47, 337 (The neurological manifestations of systemic lupus erythematosus)

Keeffe, E. B., Bardana, E. J., Harbeck, R. J., Pirofsky, B., and Carr, R. I. (1974) Ann. intern. Med., 80, 58 (Lupus meningitis. Antibody to deoxyribonucleic acid (DNA) and DNA: anti-DNA complexes in cerebrospinal fluid)

KIM, Y. S., AND RESNICK, J. S. (1965) Ibid., 63, 115 (Hypoglycorrhachia with meningeal carcinomatosis. Report of two cases)

LINDSTRöm, F. D., AND ANDERs, G. S. (1975) Arthr. and Rheum., 18, 413 (Cerebrospinal fluid changes in systemic lupus erythematosus with and without central nervous system involvement)

Lusins, J. O., AND SzIIAGYI, P. A. (1975) Amer. J. Med., 58, 857 (Clinical features of chorea associated with systemic lupus erythematosus)

OSLER, W. (1895) Amer. J. med. Sci., 110, 629 (On the visceral complications of erythema exudativum multiforme)

Penn, A. S., AND Rowan, A. J. (1968) Arch. Neurol., 18, 337 (Myelopathy in systemic lupus erythematosus)

Petz, L. D., Sharp, G. C., Cooper, N. R., AND Irvin, W. S. (1971) Medicine, 50, 259 (Serum and cerebral spinal fluid complement and serum autoantibodies in systemic lupus erythematosus)

Prockop, L. D. (1972) Delaware med. J., 44, 278 (Low cerebrospinal fluid sugar syndromes)

Sergent, J. S., LoCkshin, M. D., KLempNer, M. S., AND Lipsky, B. A. (1975) Amer. J. Med., 58, 644 (Central nervous system disease in systemic lupus erythematosus. Therapy and prognosis)

Siegel, M., AND Seelenfreund, M. (1965) J. Amer. med. Ass., 191, 77 (Racial and social factors in systemic lupus erythematosus)

SteKERT, R. G., AND ClARK, E. C. (1955) Neurology, 5, 84 (Neurological signs and symptoms as early manifestations of systemic lupus erythematosus)

SILBERBERG, D. H., AND LATIES, A. M. (1973) Arch. Neurol., 29, 88 (Increased intracranial pressure in disseminated lupus erythematosus)

Sil Verstein, A. (1963) N. York St. J. Med., 63, 2942 (Cerebrovascular accidents as the initial major manifestation of lupus erythematosus)

StewART, G., AND BASTBN, A. (1975) Ann. intern. Med., 83, 733 (Lupus erythematosus and brain scanning)

Trevor, R. P., Sondheimer, F. K., Fessel, W. J., AND WolPert, S. M. (1972) Neuroradiology, 4, 202 (Angiographic demonstration of major cerebral vessel occlusion in systemic lupus erythematosus)

Trimble, R. B., Townes, A. S., Robinson, H., Kaplan, S. B., Chandler, R. W., Hannissian, A. S., and MASI, A. T. (1974) Arthr. and Rheum., 17, 184 (Preliminary criteria for the classification of systemic lupus erythematosus. Evaluation in early diagnosed S.L.E. and rheumatoid arthritis)

WiEDERHOLt, W. C., AND SIEKERT, R. G. (1965) Neurology, 15, 1147 (Neurological manifestations of sarcoidosis) 